\title{
PREVALENCE OF COLOUR BLINDNESS IN YOUNG BANGLADESHIS
}

\author{
MD. Shahidul Islam, Proyash RoY* and SaAdleE SheHreen \\ Department of Genetic Engineering and Biotechnology, University of Dhaka, \\ Dhaka-1000, Bangladesh
}

Key words: Color vision deficiency, Protan, Deuteran, Ishihara color plates

Humans are distinguishable from non-primates by their trichromatic vision. In human, different combinations of the primary colors (red, green and blue) produce uniquecolor sensation ${ }^{(1)}$. Three spectrally-distinct types of cone photoreceptors in the retina are responsible for the discrimination of colors. They are known as short, medium and long wavelength sensitive cones which can sense light, at around 420, 530 and 560 $\mathrm{nm}$, respectively. The location of red/green pigment genes are on the long arm of $X$ chromosome ( $\mathrm{Xq} 28$ ) while blue pigment gene resides on the chromosome 7 of the human genome $^{(2)}$. Color blindness or color vision deficiencies (CVD), sometimes, occurs due to different forms of mutation, for instance, missense mutation in hybrid long/medium (LM) cone opsin genes known as OPN1LW and OPNL1MW which are arranged in a head-to-tail tandem array on the $\mathrm{X}$ chromosome ${ }^{(2,3)}$. Although, CVD is a hereditary trait but it is also reported that some acquired properties such as damage to eyes, nerves, brain; metabolic disorder like diabetes, sickle cell anemia; drugs (e.g., plaquenil, digoxin, ethambutols, chloroquineetc); and some other chemicals may cause color blindness ${ }^{(4)}$. Color blind people may suffer from partial (-anomaly) or complete (-anopia) inability to sense any of the primary colors. Red-green colorblindness is the most prevalent form of CVD which can be broadly categorized into protan (red) and deutan (green) according to the abnormality of sensing red and green color, respectively ${ }^{(2)}$. Absence or anomaly in L-cone function is known as protan defects whereas deutan defects is characterized by disruption of M-cone function. Individuals with complete absence of photopigment of the green or red cone suffer from deuteranopia or protanopia. On the other hand, deuteranomaly or protanomaly arises due to the shifting of photopigment response of the green cones towards the red cones or vice versa ${ }^{(2,3,5)}$. Most forms of color blindness are sex-linked genetic disorders that are transmitted from parent to offspring. Due to its $\mathrm{X}$-linked recessive inheritance, the disease is relatively more commonly expressed in males where about $8.0 \%$ of all women are its carrier(2). Though colorblindness is a nonfatal disorder, affected individuals suffer from various difficulties in different stages of

*Author for correspondence: <proyash.roy@du.ac.bd>. 
life and in many cases their professional lives can be disturbed. For example, a study has shown that around 8\% of all Dutch gastrointestinal endoscopist suffers from CVD which affects their diagnostic skills ${ }^{(6)}$. The prevalence of congenital red-green CVD among dental practitioners of aesthetic dentistry in Karachi, Pakistan is about $4.6 \%{ }^{(7)}$. As a whole, almost $8-9 \%$ of world population is affected by this genetic phenomenon ${ }^{(1)}$. A multi-ethnic pediatric eye disease study conducted upon children in South California found that CVD among boys was 1.4\% for black, 3.1\% for Asian, 2.6\% for Hispanic and $5.6 \%$ for non-Hispanic white children whereas the prevalence in girls was 0.0 to $0.5 \%$ for all ethnicities ${ }^{(8)}$. Some other studies revealed that 7 - $9 \%$ Caucasian males and $1 \%$ Caucasian females suffer from CVD. On the other hand, for black males and females the prevalence is only 4 and $0.8 \%$, respectively. The prevalence in young Jordanians is reported as $8 \%{ }^{(1)}$. Very few studies have been carried out in Bangladesh in comparison with other SAARC countries and data are still inadequate to determine the actual scenario of CVD in Bangladesh. A study conducted in 2008 on 500 school going children of Dhaka city showed the percentage of color blindness among the subject to be only $1 \%{ }^{(9)}$ which is, however, a clear deviation from some other studies. For instance, a study on medical and dental students of Mymensing Medical College (MMC), Bangladesh during the year 2013, found the prevalence of colorblindness to be $3.35 \%$ (male $-8.04 \%$, female $-0.66 \%)^{(10)}$. The aim of our study was to estimate the prevalence of red/green color blindness among young individuals of around 18 to 28 years of age, currently, living in Dhaka, Bangladesh.

A sample of unrelated individuals belonging to both sex ( $\mathrm{n}=302$ students; male $=$ 249 , female $=53$ ) were binocularly tested for red/green colorbliness. The sample included randomly selected students, young faculty members and staff from different residential halls and departments of the University of Dhaka. The color vision deficiency was determined by using Ishihara pseudo-isochromatic color vision test (24 plates edition) ${ }^{(11)}$. As all the participants were able to read numerals, only the 1 st 17 plates of the 24 plates edition were used. Questionnaire was prepared to take account of the test data and also other general information about participants' disease profile (if any), normal visual acuity, age, height, weight, gender, as well as the smoking habit (if applicable) etc. The test was conducted in adequate day light and by taking prior informed consent from the individual. The color vision testing plates were held at a distance of $75 \mathrm{~cm}$ from the person and angled right to the line of vision ${ }^{(11)}$. Each of the participants was asked to read the numbers seen on the test plates from no. 01 to 17. The participants had to answer within 3 seconds for each plate. The test was repeated once again for those individuals who were tested positive in the first instance. All individuals, whether colorblind or not, could identify the number 12, when plate no. 01 was shown. Next 12 plates (Plate no. 02 to 13) were such that individuals with normal color vision see a definite number whereas CVD individuals see something wrong or nothing. Normal people are unable to detect any number in plate no. 14 and 15, 
but most red-green color blinds see some specific number in such plates. The last two plates (no. 16 and 17) were used to differentiate between protans and deutans. In the experiment, if 13 or more plates were read correctly, the vision was regarded as normal otherwise the individual was recorded as CVD person. Allelic and genetic frequencies were calculated according to the Hardy-Weinberg equilibrium method $\left(\mathrm{p}^{2}+\mathrm{q}^{2}+2 \mathrm{pq}=1\right.$; $\mathrm{C}$ allele $=\mathrm{p}$ and $\mathrm{c}$ allele $=\mathrm{q}$ ). The level of heterozygosity was calculated using the following formula:

Heterozygosity $=1-\Sigma$ Ho; where Ho is the homozygosity of the allele, $\mathrm{Ho}=\Sigma \mathrm{Pi}^{2}(\mathrm{Pi} \text { represents the allele } \mathrm{c} \text { or } \mathrm{C})^{(2,3)}$

A total of 21 non-consanguineous color blind individuals (out of 302) were found in the study with a statistically significant difference between females and males. A total of 20 males (deutan: 19, protan: 01) were found as colorblind out of 249, whereas only 1 female (deutan) was found positive out of the total 53 female samples. This corresponds to the phenotypic frequency of $8.03 \%$ for male (deutan: $7.63 \%$, protan: $0.4 \%$ ) and $1.89 \%$ for female. For male, the phenotypic frequency equals to genotypic or allelic frequency as they have only one $\mathrm{X}$-chromosome. However, for females three different genotypes are possible; homozygous dominant (CC), homozygous recessive (cc) and heterozygous (Cc). Table 1 shows all the allele or genotype frequencies found in the study for males and females.

Table 1. Observed genotypic frequency of color blindness associated alleles.

\begin{tabular}{|c|c|c|c|c|c|c|c|c|c|c|c|}
\hline \multirow{3}{*}{ Type } & \multicolumn{4}{|c|}{ Male $(\mathrm{n}=249)$} & \multicolumn{7}{|c|}{ Female $(n=53)$} \\
\hline & \multirow[t]{2}{*}{$\mathrm{n}$} & \multirow[t]{2}{*}{$\%$} & \multicolumn{2}{|c|}{$\begin{array}{l}\text { Allele/genotype } \\
\text { freq. }\end{array}$} & \multirow[t]{2}{*}{$\mathrm{n}$} & \multirow[t]{2}{*}{$\%$} & \multicolumn{2}{|c|}{$\begin{array}{l}\text { Allele } \\
\text { freq. }\end{array}$} & \multicolumn{3}{|c|}{$\begin{array}{l}\text { Genotype } \\
\text { freq. }\end{array}$} \\
\hline & & & $\mathrm{C}(\mathrm{Y})$ & $c(Y)$ & & & $\mathrm{c}$ & C & $\mathrm{CC}$ & $\mathrm{Cc}$ & $\mathrm{cc}$ \\
\hline $\begin{array}{l}\text { Green type } \\
\text { (Deutan) }\end{array}$ & 19 & 7.63 & 0.924 & 0.076 & 1 & 1.89 & 0.137 & 0.863 & 0.744 & 0.237 & 0.019 \\
\hline $\begin{array}{l}\text { Red type } \\
\text { (Protan) }\end{array}$ & 1 & 0.40 & 0.996 & 0.004 & 0 & 0.00 & 0.00 & 0.00 & 1.000 & 0.000 & 0.000 \\
\hline Total & 20 & 8.03 & 0.920 & 0.080 & 1 & 1.89 & 0.137 & 0.863 & 0.744 & 0.237 & 0.019 \\
\hline
\end{tabular}

In mid-1990s the hypothesis of colorblindness was experimentally proven by a group of scientists in England through analyzing the opsin gene from the DNA sample of retina of the renowned chemist John Dalton ${ }^{(12)}$. However, as colorblindness is a non-lethal condition, scientific community, so far, paid trivial attention to the disorder. Nonetheless, as mentioned earlier, some people face considerable problem during their occupational and personal life due to this non-fatal disease. It is, therefore, useful to have an idea 
regarding the prevalence of colorblindness in any particular region to raise awareness and lessen the discomfort of the colorblind people through palliative measures. The objective of our study was to determine the prevalence of color blindness among young Bangladeshis in order to construct a statistical data frame for related research in future. In our study, the percentage of color blindness among males was 8.03 which correlated with the study on the students of MMC, Bangladesh(10). The percentage shows similarity with some other countries or communities, for instance, with Denmark $(8.61 \%)^{(2,13)}$, Kurds of Iran $(8.1 \%)^{(1)}$ and Iraq $(8.2 \%)^{(14)}$. In India, two different studies conducted on the population of Jammu province and Manipur state have found the percentage of color blindness in males to be 7.52 and $8.73 \%$, respectively ${ }^{(2.3)}$. In some other regions, however, the reported occurrence rate of color blindness is relatively low. For instance, only $3.8 \%$ and $3.9 \%$ of school going boys in Kathmundu and Pokhara of Nepal have been found to be color blind, respectively(15,16). Besides, only $4 \%$ of Africans, $5.6 \%$ of South-West Asian populations and about $1 \%$ of South American Indians and Eskimos are CVD positive ${ }^{(3)}$. Although, our study was conducted on individuals currently living in Dhaka, most of the participants originally came from different parts of Bangladesh. As a result, our sample includes more or less demographic variation. No significant correlation was found between colorblindness and blood groups, height, weight, smoking habit, other diseases etc. Ishihara color vision test was originally designed to check only for red-green color blindness. Thus, other rare forms of colorblindness, for example, tritanomaly or tritanopia were not covered by this study. A larger sample size would certainly put more confidence on the results, however, the study will, nonetheless, provide a rough idea about the colorblindness scenario in Bangladesh. We believe this population-based study will add some value in the field of studying ophthalmic defects in Bangladesh as well ascreate scope for introducing pre- or post-marital genetic counseling and palliative actions to alleviate the disease phenomena.

\section{References}

1. Al-Aqtum MT and MH Al-Qawasmeh 2001. Prevalence of colour blindness in young Jordanians. Ophthalmologica 215: 39-42.

2. Fareed M, MA Anwar and M Afzal 2015. Prevalence and gene frequency of color vision impairments among children of six populations from North Indian region. Genes \& Diseases 2(2): 211-218.

3. Shah A, R Hussain, M Fareed and M Afzal 2013. Prevalence of red-green color vision defects among Muslim males and females of Manipur, India. Iranian Journal of Public Health 42(1): 16-24.

4. Ganong WF 2005. Review of Medical Physiology. 22th edition, McGraw-Hill, London.

5. Cole BL 2007. Assessment of inherited colour vision defects in clinical practice. Clinical and Experimental Optometry 90(3): 157-175. 
6. Koningsberger JC, D Van Norren, JC Van Niel and W Dekker 1994. Does color vision deficiency in the endoscopist influence the accuracy of endoscopic diagnosis? An anonymous study with Dutch gastrointestinal endoscopists. Endoscopy 26(6): 549-553.

7. Yousuf W, BD Moiz Khan and SM Kazmi 2015. Prevalence of color-blindness among practitioners of esthetic dentistry in Karachi, Pakistan. International Journal of Clinical Dentistry 8(1): 37-41.

8. Xie JZ, K Tarczy-Hornoch, J Lin, SA Cotter, M Torres and R Varma 2014. Color vision deficiency in preschool children: the multi-ethnic pediatric eye disease study. Ophthalmology 121(7): 1469-1474.

9. Yasmin A, N Janan and R Akhter 2009. Assessment of colour blindness and erythrocyte G6PD enzyme status among the school children of Dhaka city. Journal of Bangladesh Society of Physiologist 4(2): 64-70.

10. Hossain MI, L Nahar, MS Dad, MF Islam and MM Uddin 2013. Prevalence of colour blindness among the first year medical and dental students of Mymensingh Medical College, Bangladesh. Mymensingh Medical Journal 22(4): 661-664.

11. Ishihara S 1972. The Series of Plates Designed as a Test for Color-blindness, 24 Plates edition, Kanehara Shuppan Co., Tokyo, Japan.

12. Nelson DL and MM Cox 2008. Lehninger Principles of Biochemistry, 5th edition, Macmillan, pp. 466.

13. Norn M 1997. Prevalence of congenital colour blindness among Inuit in East Greenland. Acta Ophthalmologica Scandinavica 75(2): 206-209.

14. Al-Amood WS, Mohammed SG, Al-Sanawi DA, Radhi AR, Rehman BA 1981. Incidence of colour blindness in Iraqi Arabs. Human Heredity. 31(2): 122-123.

15. Shrestha RK, MR Joshi, S Shakya and R Ghising 2010. Color vision defects in school going children. Journal of Nepal Medical Association 50(180): 264-266

16. Niroula DR and CG Saha 2010. The incidence of color blindness among some school children of Pokhara, Western Nepal. Nepal Medical College Journal 12(1): 48-50. 